\title{
The critical rate of horizontal wells in bottom- water reservoirs with an impermeable barrier
}

\author{
Yue Ping ${ }^{1 *}$, Du Zhimin ${ }^{1}$, Chen Xiaofan ${ }^{1}$ and Liang Baosheng ${ }^{2}$ \\ ${ }^{1}$ State Key Laboratory of Oil \& Gas Reservoir Geology and Exploitation Engineering, Southwest Petroleum University, \\ Chengdu, Sichuan 610500, China \\ ${ }^{2}$ Chevron Energy Technology Company, 1500 Louisiana Street, Room 25002, Houston, TX 77002 USA
}

(C) China University of Petroleum (Beijing) and Springer-Verlag Berlin Heidelberg 2012

\begin{abstract}
Barrier impacts on water cut and critical rate of horizontal wells in bottom water-drive reservoirs have been recognized but not investigated quantitatively. Considering the existence of impermeable barriers in oil formations, this paper developed a horizontal well flow model and obtained mathematical equations for the critical rate when water cresting forms in bottom-water reservoirs. The result shows that the barrier increases the critical rate and delays water breakthrough. Further study of the barrier size and location shows that increases in the barrier size and the distance between the barrier and oil-water contact lead to higher critical rates. The critical rate gradually approaches a constant as the barrier size increases. The case study shows the method presented here can be used to predict the critical rate in a bottom-water reservoir and applied to investigate the water cresting behavior of horizontal wells.
\end{abstract}

Key words: Horizontal well, bottom-water reservoir, barriers, critical rate, cresting

\section{Introduction}

In order to control the coning or cresting problem in bottom water-drive reservoirs, many researchers have investigated the flow mechanisms and developed methods to calculate the critical rate (Muskat and Wyckoff, 1935; Chierici et al, 1964; Chaperon, 1986; Guo and Lee, 1992a; 1992b; Aulie et al, 1993; Fan and Lin, 1994; Gunning et al, 1999; Permadi and Jayadi, 2010; Zhang et al, 2011) and to predict water breakthrough time (Papatzacos et al, 1989; Ozkan and Raghavan, 1990; Cheng et al, 1994; Bahadori, 2010) and reduce water cut (Smith and Pirson, 1963; Wojtanowicz et al, 1994; Siddiqi and Wojtanowicz, 2002; Ould-Amer et al, 2004; Jin et al, 2009). The maximum water free oil production rate is termed the critical rate. The critical rate of horizontal wells calculated from previous methods (Chaperon, 1986; Fan and Lin, 1994) was much less than the actual oil production rate in some bottom water reservoirs, but some wells produced only oil and did not produce water for a long time (Permadi et al, 1995, Yue et al, 2009). Such phenomena are due to two main reasons. First, the start-up condition should be applied in the calculation of critical rate (Yue et al, 2009). Second, geological conditions are far more complex than the models consider, as for example there may be impermeable barriers in reservoir formations. Barriers in the reservoir formations have been reported to significantly

*Corresponding author. e-mail: yuepingaa@126.com

Received July 14, 2011 increase the critical rate and delay the water breakthrough time (Karp et al, 1962; Strickland, 1974; Li and Song, 1993; Li, 1997; Gourley and Ertekin, 1977; Hou, 2007; Zhang et al, 2008). Barriers by definition are generally the impermeable or low-permeability rock layers which prevent or reduce fluid penetration in the reservoir. Some experiments have been conducted to study water coning or cresting in reservoir development (Chierici et al, 1964; Khan, 1970; Permadi, 1996; Mungan, 1975; Shirman, 1998; Aggour and Khana, 2001). The impacts of barrier size and position on the bottom water coning in vertical wells have been investigated ( $\mathrm{Li}$ and Song, 1993; Li, 1997; Siddiqi and Wojtanowicz, 2002). However, there is little work about barriers affecting the bottom water cresting in horizontal wells. In particular, no formula is available to calculate the critical rate in horizontal wells in bottom water reservoirs with barriers, which is the focus of this paper. This paper develops a horizontal well flow model with a barrier in a bottom water reservoir and obtains mathematical equations for the critical rate when water cresting occurs. Sensitivity studies of the barrier size and position are then given and a case study is presented.

\section{The model of impermeable barriers}

Impermeable barriers, also named interbeds, have zero permeability. The interbed theory can be used to study water cresting of horizontal wells in bottom water reservoirs. Li and his coworker ( $\mathrm{Li}$ and Song, 1993; Li, 1997) firstly proposed the interbed theory and developed a model to investigate bottom water coning in vertical wells with barriers. On the 
base of Li's theory, the authors introduced the equivalent flow resistance method and developed a formula to predict the critical rate of horizontal wells in bottom water reservoirs.

\subsection{Model assumptions and descriptions}

Fig. 1 is a sketch of a horizontal well penetrating an oilbearing formation and an impermeable barrier horizontally extended in the oil formation. The barrier is assumed to be horizontal, just below the well. The distances from the barrier to the top and bottom of the oil formation are $a$ and $c$, respectively. The barrier width is $b$ and its thickness is ignored. Other conditions are the same as those described in the previous literature (Yue, et al, 2009). The top boundary is closed and the bottom boundary is constant pressure $p_{e}$. The reservoir thickness is $h$. The distance between the horizontal well and the oil-water interface is $z_{\mathrm{w}}$. The length of the horizontal well is $L$. The horizontal well radius is $r_{\mathrm{w}}$.

According to the interbed theory, water coning occurs first at points $C$ and $C^{\prime}$, which are below the barrier end points $M$ and $M^{\prime}$. The shape of water cresting is shown in Fig. 1.

According to previous research (Borisov, 1984; Giger et al, 1984; Giger, 1986; Joshi, 1988; Chen, 2008), the fluid flow to the horizontal well is divided into two regions: the far away region and the near-wellbore flow region. The entire flow process of this model is also divided into two stages. At the first stage, the fluid on the left side flows from the bottom to the $M N$ plane. The second stage the fluid flows from the $M N$ plane into the wellbore. The flow process on the right side is identical. In the following, a method to simplify and solve the two flow stages will be introduced.

For the first stage, the right upper boundary of the virtual well $M$ is closed. For no fluid supply, the left upper boundary also can be treated as a closed boundary. Assuming that there is no interference from the virtual well $M^{\prime}$, the horizontal well productivity formula (Fan, 1993) can be used to calculate the productivity of the virtual well $M^{\prime}$. The followup interference between wells $M$ and $M^{\prime}$ can use parameter $\gamma$ to later amend the model. The principle of equal length is applied and the $M N$ plane is treated as a production well with a wellbore perimeter equal to the length of $M N$. Because the top boundary is sealed and the bottom boundary pressure is constant, the fluid to the $M N$ plane mainly comes from the bottom of the reservoir. Fluid flow rate in the $M N$ plane is gradually increased from the point $N$ to $M$. The location of the equivalent well is set at point $M$ (shown in Fig. 1) at which the fluid flow rate is relatively high. It is assumed that the fluid flow to the equivalent well $M$ is only a portion of the total production rate. The other side $M^{\prime} N^{\prime}$ is treated similarly. Then, two equivalent wells $M$ and $M^{\prime}$ producing at the same time can generate water cresting with a shape as shown in Fig. 1.

As mentioned above, the fluid flow into the equivalent wells is a part of total flow in the first stage. A parameter $\gamma$ is introduced to describe the relationship between the flow rate of the equivalent well $Q_{1}$ and the total flow rate of the actual well $Q_{2}$. Parameter $\gamma$ is also used to amend the calculated productivity when two equivalent wells interfere with each other. It is a ratio between the total flow rate of the production

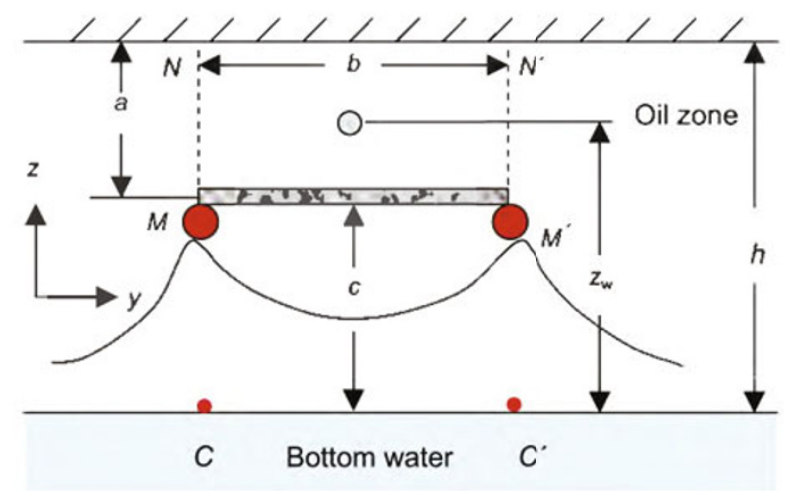

Fig. 1 The sketch of a horizontal well with a barrier in a bottom water rescrvoir

well and the rate flow through the equivalent wells $M$ and $M^{r}$. In other words, it is the ratio between the rate of flow through the $M N$ plane in the first flow stage and the flow rate into the equivalent well $M$. Because the equivalent wells $M$ and $M$ are symmetrical, a material balance leads to the relationship between $Q_{1}$ and $Q_{2}$

$$
Q_{2}=2 \gamma Q_{1}
$$

where $Q_{1}$ is the flow rate of the equivalent well at the first flow stage, $\mathrm{m}^{3} / \mathrm{d} ; Q_{2}$ is the total flow rate of the actual well at the second flow stage, $\mathrm{m}^{3} / \mathrm{d} ; \gamma$ is parameter for the relationship between $Q_{1}$ and $Q_{2}$

\subsection{Flow at the first stage}

At the first flow stage, the problem can be simplified as two equivalent horizontal production wells $M$ and $M^{\prime}$ near the top boundary in a bottom water reservoir with a formation thickness of $c$. The productivity of a horizontal well in the bottom water reservoir (Fan, 1993) can be applied:

$$
Q=\frac{2 \pi K L\left(\Phi_{\mathrm{c}}-\Phi_{\mathrm{wf}}\right)}{B_{\mathrm{o}} \mu_{\mathrm{o}}\left(\ln \frac{4 h}{\pi r_{\mathrm{w}}}+\ln \operatorname{tg} \frac{\pi z_{\mathrm{w}}}{2 h}\right)}
$$

where $Q$ is the productivity of a horizontal well, $\mathrm{m}^{3} / \mathrm{d} ; \Phi_{\mathrm{e}}$ is the constant potential on the bottom boundary, $\mathrm{MPa}$; $\Phi_{\mathrm{wr}}$ is the bottom hole flowing potential, MPa; $K$ is the formation permeability, $\mu \mathrm{m}^{2} ; L$ is the horizontal well length, $\mathrm{m} ; B_{0}$ is the oil formation volume factor; $\mu_{0}$ is the oil viscosity, $\mathrm{mPa} \cdot \mathrm{s} ; h$ is the thickness of the reservoir, $\mathrm{m} ; r_{\mathrm{w}}$ is the wellbore radius, $\mathrm{m}$; $z_{\mathrm{w}}$ is the distance between the horizontal well and the bottom boundary, $m$.

The equivalent length method is used to determine the radius of the image well:

$$
r_{\mathrm{w}}^{\prime}=\frac{a}{2 \pi}
$$

where $r_{\mathrm{w}}{ }^{\prime}$ is the equivalent wellbore radius, $\mathrm{m} ; a$ is the distance between the barrier and the top boundary, $\mathrm{m}$.

Given the potential difference $\Delta \Phi_{1}$, the productivity of the image wells $M$ or $M^{\prime}$ is

$$
Q_{1}=\frac{2 \pi K L \Delta \Phi_{1}}{B_{0} \mu_{0} A}
$$


with

$$
\begin{aligned}
& A=\left(\ln \frac{8 c}{a}+\ln \operatorname{tg} \frac{\pi z_{\mathrm{w}}{ }^{\prime}}{2 c}\right) \\
& z_{\mathrm{w}}{ }^{\prime}=c-r_{\mathrm{w}}^{\prime} / 2
\end{aligned}
$$

where $\Delta \Phi_{1}$ is the potential difference at the first flow stage, $\mathrm{MPa} ; c$ is the distance between the barrier and the bottom boundary, $\mathrm{m}$.

\subsection{Flow at the second stage}

The second flow stage, the fluid flow from $M N$ plane to the horizontal well. The rectangle region $M N N^{\prime} M^{\prime}$ is selected as the study area, which is equivalent to an edge-water-drive reservoir with sealed top and bottom boundaries, and left and right water supply boundaries. Thus, the productivity of a horizontal well in an edge-water drive reservoir can be used (Yuc, 2010):

$$
Q=\frac{2 \pi K L \Delta \Phi}{\mu_{\mathrm{o}} B_{\mathrm{o}}\left[\ln \left(\operatorname{ch} \frac{2 \pi r_{\mathrm{e}}}{h}\right)-\ln \frac{\pi r_{\mathrm{w}}}{h} \sin \frac{\pi z_{\mathrm{w}}}{h}\right]}
$$

where $r_{\mathrm{e}}$ is the radius of the edge-water-drive reservoir drainage boundary, $\mathrm{m}$.

Given the potential difference $\Delta \Phi_{2}$ in the second stage, the productivity of the actual production well can be obtained from Eq. (5) and can be simplified as:

$$
Q_{2}=\frac{2 \pi K L \Delta \Phi_{2}}{\mu_{\mathrm{o}} B_{\mathrm{o}} B}
$$

with

$$
B=\operatorname{lnch} \frac{\pi b}{a}-\ln \frac{\pi r_{\mathrm{w}}}{a} \sin \frac{\left(z_{\mathrm{w}}-c\right)}{a}
$$

where $\Delta \Phi_{2}$ is the potential difference at the second flow stage, $\mathrm{MPa} ; b$ is the width of the barrier, $\mathrm{m}$.

According to the start-up condition of bottom water rising (Yue, et al, 2009), the following equation is the start-up condition to form water cresting:

$$
-\frac{d \Phi_{1}}{\mathrm{~d} z}=\left(\rho_{\mathrm{w}}-\rho_{\mathrm{o}}\right) g
$$

where $\rho_{\mathrm{o}}$ is the oil density, $\mathrm{kg} / \mathrm{m}^{3} ; \rho_{\mathrm{w}}$ is the water density, $\mathrm{kg} /$ $\mathrm{m}^{3} ; g$ is the gravitational constant, $\mathrm{m} / \mathrm{s}^{2}$.

At the first flow stage, the potential gradient below the image wells $M$ or $M^{\prime}$ is (Fan, 1993; Yue et al, 2009).

$$
-\frac{\partial \Phi}{\partial z}=\frac{\mu_{0} B_{0} Q}{4 K h L} \frac{\sin \frac{\pi\left(z+z_{w}\right)}{2 h}-\sin \frac{\pi\left(z-z_{w}\right)}{2 h}}{\sin \frac{\pi\left(z+z_{w}\right)}{2 h} \sin \frac{\pi\left(z-z_{w}\right)}{2 h}}
$$

Substituting $z=0, z_{\mathrm{w}}{ }^{\prime}=c-r_{\mathrm{w}}{ }^{\prime} / 2$ and $h=c$ into Eq. (8) yiclds the potential gradient at the oil-water contact point $C$ generated by the image well $M$.

$$
-\frac{\partial \Phi_{1}}{\partial z}=\frac{\mu_{\mathrm{o}} B_{\mathrm{o}} Q_{1}}{2 K c L} \sin \frac{\pi z_{\mathrm{w}}{ }^{\prime}}{2 c}
$$

The potential gradient at point $C^{\prime}$ is the same.

Combining Eqs. (7) and (9) gives the critical rate at the first flow stage:

$$
Q_{1}=\frac{2 K c L\left(\rho_{\mathrm{w}}-\rho_{\mathrm{o}}\right) g}{\mu_{\mathrm{o}} B_{\mathrm{o}}} \sin \left(\frac{\pi z_{\mathrm{w}}{ }^{\prime}}{2 c}\right)
$$

Such rate consequently determines the reservoir critical rate $Q_{\mathrm{m}}$

$$
Q_{\mathrm{nu}}=Q_{2}=2 \gamma Q_{1}
$$

where $Q_{\mathrm{m}}$ is the critical rate for the oil formation with a impermeable barrier, $\mathrm{m}^{3} / \mathrm{d}$.

Combining Eqs. (4) and (10) gives the critical potential difference at the first flow stage.

$$
\Delta \Phi_{1}=\frac{A c\left(\rho_{\mathrm{w}}-\rho_{\mathrm{o}}\right) g}{\pi} \sin \left(\frac{\pi z_{\mathrm{w}}{ }^{\prime}}{2 h}\right)
$$

From Eqs. (1), (6) and (10), the potential difference at the sccond flow stage is

$$
\Delta \Phi_{2}=\frac{2 B \gamma c\left(\rho_{\mathrm{w}}-\rho_{\mathrm{o}}\right) g}{\pi} \sin \left(\frac{\pi z_{\mathrm{w}}{ }^{\prime}}{2 c}\right)
$$

Therefore, the critical potential difference is

$$
\Delta \Phi_{\mathrm{m}}=\Delta \Phi_{1}+\Delta \Phi_{2}
$$

According to the relationship between the potential and pressure differences, the critical pressure difference is

$$
\Delta p_{\mathrm{m}}=\Delta \Phi_{\mu \mathrm{u}}+\rho_{\mathrm{o}} g z_{\mathrm{w}}
$$

\section{Determination of the parameter $\gamma$}

Parameter $\gamma$ is affected by the location and size of the barrier, i.e., parameters $c, h$ and $a$. When $b=0$, that is, no barrier exists, the problem is simplified into an isotropic bottom water reservoir. According to Eq. (10), if there is no barrier the critical rate $Q_{\mathrm{m}}{ }^{\prime}$ is

$$
Q_{\mathrm{m}}{ }^{\prime}=\frac{2 K h L\left(\rho_{\mathrm{w}}-\rho_{\mathrm{o}}\right) g}{\mu_{\mathrm{o}} B_{\mathrm{o}}} \sin \left(\frac{\pi z_{\mathrm{w}}}{2 h}\right)
$$

where $Q_{\mathrm{n}}{ }^{\prime}$ is the critical rate for the oil formation without an impermeable barrier, $\mathrm{m}^{3} / \mathrm{d}$.

Let $Q_{\mathrm{m}}=Q_{\mathrm{m}}{ }^{\prime}, \gamma_{\mathrm{o}}$ can be obtained from Eqs. (10), (11) and (16):

$$
\gamma_{0}=\frac{h \sin \left(\frac{\pi z_{w}}{2 h}\right)}{2 c \sin \left(\frac{\pi z_{w}{ }^{\prime}}{2 c}\right)}
$$


When $b=2 r_{\mathrm{e}}$, that is, the barrier width is equal to the radius of the drainage boundary, the problem is simplified into an edge water reservoir problem. Based on physical experiments in the literature, the following empirical formula is applied

$$
\gamma=\gamma_{0}\left(1+\ln \left(\frac{b c}{r_{\mathrm{e}}}+1\right)\right) \quad\left(0 \leq b \leq 2 r_{\mathrm{e}}\right)
$$

\section{Analysis of examples and case study}

\subsection{The example calculation}

SI units are used in this case study and the basic information is as follows: The horizontal well length in a bottom water reservoir is $350 \mathrm{~m}$. The oil formation thickness is $40 \mathrm{~m}$. The pressure at the oil-water contact is $25 \mathrm{MPa}$. The reservoir oil viscosity is $15 \mathrm{mPa} \cdot \mathrm{s}$. The densities of reservoir water and oil are 1,050 and $850 \mathrm{~kg} / \mathrm{m}^{3}$, respectively. The oil formation volume factor is 1.05 . The isotropic permeability is $0.15 \mu \mathrm{m}^{2}$. The wellbore radius is $0.1 \mathrm{~m}$ and the distance between the horizontal well and the oil-water contact is $30 \mathrm{~m}$.

When no barrier exists, the critical parameters of the horizontal well are calculated with Eq. (16). When a horizontal impermeable barrier is present in the oil zone and $20 \mathrm{~m}$ above the oil-water contact $(c=20 \mathrm{~m})$. The barrier width is $20 \mathrm{~m}$. A horizontal well is drilled above the barrier. and the supply radius in the $Y$ direction is $r_{\mathrm{e}}=200 \mathrm{~m}$. Other data are the same as above. Eq. (10) can be used to calculate $Q_{1}$, and Eq. (18) is used to obtain $\gamma$. Then Eq. (11) is used to obtain the critical rate. Eqs. (14) is used to obtain the critical potential difference, and with Eq. (15) is used to obtain the critical pressure difference. Table 1 lists the calculated results.

Table 1 Calculated results

\begin{tabular}{lccc}
\hline & $\begin{array}{c}\text { Critical rate } \\
\mathrm{m}^{3} / \mathrm{d}\end{array}$ & $\begin{array}{c}\text { Critical potential } \\
\text { difference, } \mathrm{MPa}\end{array}$ & $\begin{array}{c}\text { Critical pressure } \\
\text { difference, } \mathrm{MPa}\end{array}$ \\
\hline Without barrier & 41.7 & 0.16 & 0.41 \\
With a barrier & 99.6 & 0.28 & 0.53 \\
\hline
\end{tabular}

The critical rate is $99.6 \mathrm{~m}^{3} / \mathrm{d}$ and the critical pressure difference is $0.53 \mathrm{MPa}$ in the oil formation with a barrier. Note that both the critical rate and the critical pressure in the case with a barrier are higher than the case without barriers.

\subsection{Sensitivity analysis of variables $b$ and $c$}

The variable $c$ is the distance between the horizontal well and the bottom boundary of the oil reservoir. Fig. 2 indicates the calculated critical rate when $c$ changes from 0 to $30 \mathrm{~m}$.

Changing the width of the barrier $b$ from 0 to $400 \mathrm{~m}$ also increases the critical rate, as shown in Fig. 3.

Both the barrier size and its location affect the critical rate. Fig. 2 shows that increasing the distance of the barrier to the reservoir bottom results in an increase in the critical rate. Fig. 3 shows that the barrier width has a positive impact on the critical rate. However, such effect gets slower as the barrier size continues increasing. Fig. 4 shows a comparison of the

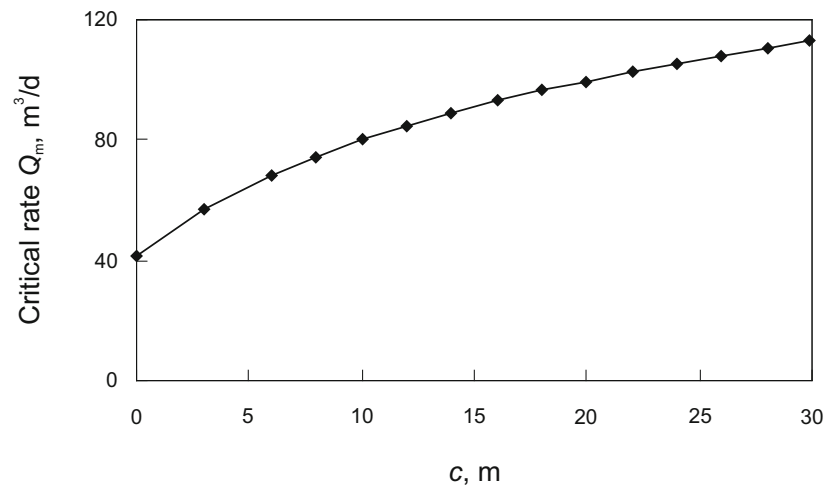

Fig. 2 Critical rate changes with the distance $c$

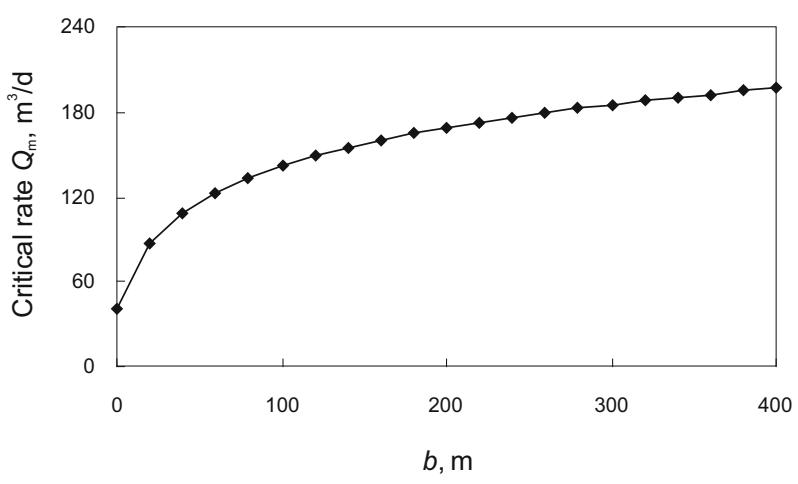

Fig.3 The critical rate changes with the width of the barrier $b$

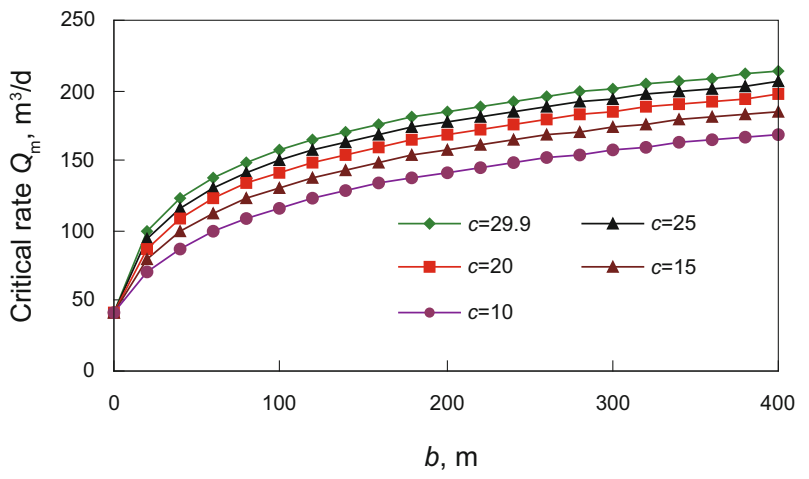

Fig. 4 A comparison of critical rates at different $b$ and $c$ values

variation of the critical rate with $b$ and $c$. When $b$ becomes close to 0 , the critical rate converges to the value $44.74 \mathrm{~m}^{3} / \mathrm{d}$, the rate for the formation without a barrier.

\subsection{Case study}

A Triassic reservoir in the Tahe oil field was selected as the research case. This reservoir is a typical bottom-waterdrive reservoir in which the bottom water energy is sufficient. Three horizontal wells, which were drilled above horizontal impermeable barriers, were used to analyze the critical rate and the performance of water breakthrough.

Some information about the horizontal wells and their daily production data are shown in Table 2, Figs. 5 and 6. 
Table 2 Parameters of reservoir and wells

\begin{tabular}{ccccccccccc}
\hline Well & $\begin{array}{c}r_{\mathrm{e}} \\
\mathrm{m}\end{array}$ & $\begin{array}{c}H \\
\mathrm{~m}\end{array}$ & $\begin{array}{c}L \\
\mathrm{~m}\end{array}$ & $\begin{array}{c}\mathrm{z}_{\mathrm{w}} \\
\mathrm{m}\end{array}$ & $\begin{array}{c}\mu_{\mathrm{o}} \\
\mathrm{mPa} \cdot \mathrm{s}\end{array}$ & $B_{\mathrm{o}}$ & $\begin{array}{c}K \\
10^{-3} \mu \mathrm{m}^{2}\end{array}$ & $\begin{array}{c}\rho_{\mathrm{o}} \\
\mathrm{g} / \mathrm{cm}^{3}\end{array}$ & $\begin{array}{c}\rho_{\mathrm{w}} \\
\mathrm{g} / \mathrm{cm}^{3}\end{array}$ & $K_{\mathrm{v}} / K_{\mathrm{h}}$ \\
\hline TK911H 200 & 15.8 & 307 & 14 & 2.78 & 1.34 & 191 & 0.76 & 1.14 & 0.75988 \\
TK921H 200 & 15.8 & 230 & 8.27 & 2.78 & 1.34 & 114 & 0.76 & 1.14 & 0.75988 \\
TK923H 200 & 16 & 144 & 14.7 & 2.78 & 1.34 & 141 & 0.76 & 1.14 & 0.75988 \\
\hline
\end{tabular}

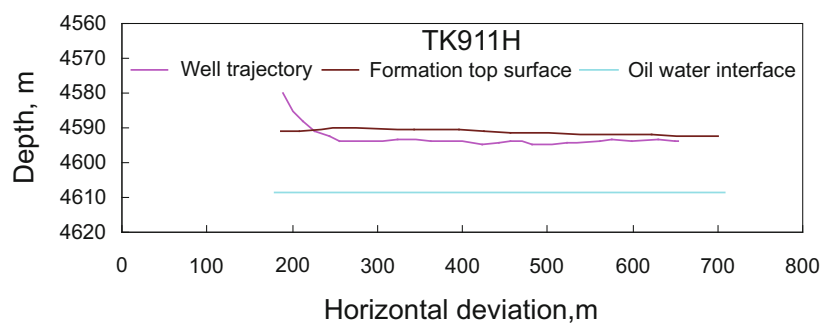

(a) Well TK911H

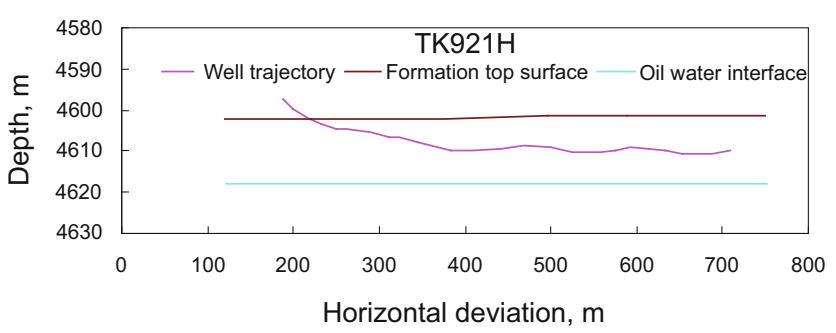

(b) Well TK921H

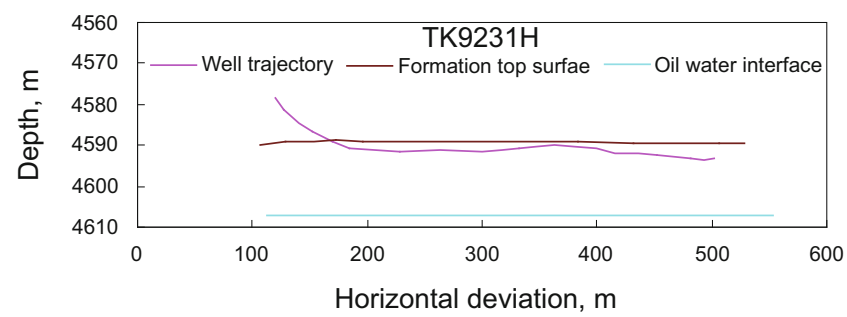

(c) Well TK923H

Fig. 5 Drilling information about three horizontal wells

The commonly-used formulas can only be used to calculate the critical rate of horizontal wells in oil formations without barriers below the horizontal wellbore. The results

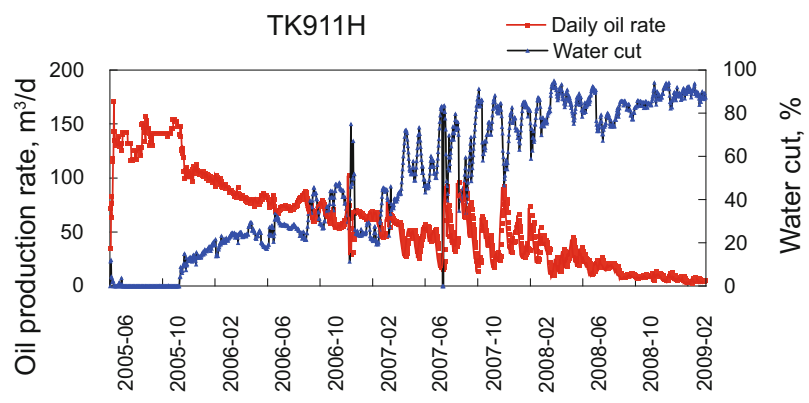

(a) Well TK911H

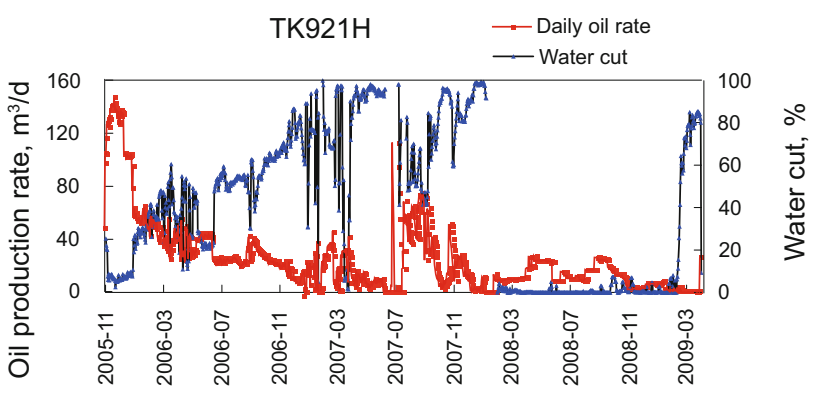

(b) Well TK921H

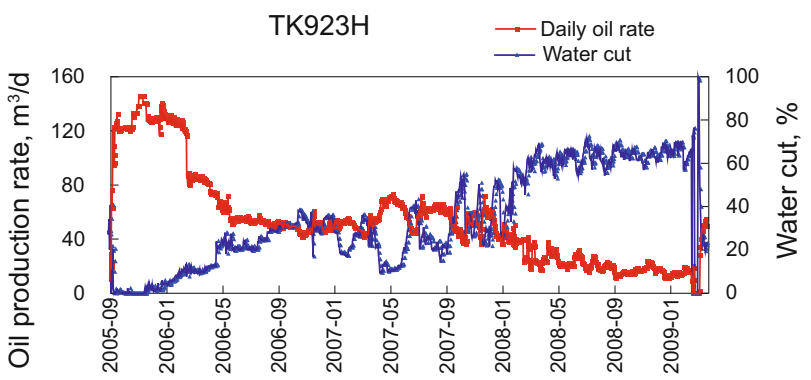

(c) Well TK923H

Fig. 6 The daily production data of three horizontal wells

calculated from the commonly-used formulas and the method proposed in this paper are listed in Table 3. Well log interpretation showed that 1 to 2 barriers were distributed below the horizontal wells and the total thickness was about 1.5 to $2 \mathrm{~m}$. The distances from the barriers to the water-oil contact of wells TK911H, TK921H, and TK923H were 8, 5 and $8 \mathrm{~m}$, respectively. Because of a lack of information, the distribution boundary of barriers in the reservoir could not be accurately described, so the value of $b$ was set at 10-50 m.

Table 3 The critical rate predicted by the commonly used formulas and the method proposed in this paper

$\left(\mathrm{m}^{3} / \mathrm{d}\right)$

\begin{tabular}{|c|c|c|c|c|c|c|c|c|c|}
\hline \multirow{2}{*}{ Well } & \multicolumn{4}{|c|}{ Commonly-used methods without considering barriers } & \multicolumn{5}{|c|}{ Method proposed in this paper considering the impermeable barrier } \\
\hline & Chaperson & Joshi & Fan & Method proposed in this paper, $b=0$ & $b=10$ & $b=20$ & $b=30$ & $b=40$ & $b=50$ \\
\hline TK911H & 20.9 & 9.90 & 54.4 & 137.4 & 168.0 & 193.1 & 214.2 & 232.6 & 248.8 \\
\hline TK921H & 3.50 & 3.80 & 18.6 & 45.8 & 56.1 & 64.4 & 71.5 & 77.6 & 83.0 \\
\hline TK923H & 8.56 & 4.40 & 18.8 & 48.5 & 59.39 & 68.2 & 75.7 & 82.21 & 87.9 \\
\hline
\end{tabular}


The common formulas do not consider the effect of impermeable barriers when calculating the critical rate. The calculated value is significantly low, so that it is difficult to apply these values in oil production. As Fig. 6(a) shows, the initial average daily production rate of Well TK911H was about $150 \mathrm{~m}^{3}$, and the well produced oil for 160 days before water appeared. When the barrier was $7 \mathrm{~m}$ long in the $Y$ direction, the calculated critical production rate is $150 \mathrm{~m}^{3} / \mathrm{d}$. Once the width of barrier $b$ is larger than $7 \mathrm{~m}$, water-free oil production will be a long period of time.

As Fig. 6(b) shows, the initial average production rate of Well TK921H was $135 \mathrm{~m}^{3} / \mathrm{d}$. The period of water-free production was about 50 days. When the impermeable barrier extends $50 \mathrm{~m}$ in the $Y$ direction, the calculated critical rate is $83.0 \mathrm{~m}^{3} / \mathrm{d}$, which is lower than the initial average production rate. It is obviously that the initial average production rate was too high so that the bottom water rise was too fast, and the period of water-free oil production was merely 50 days.

As Fig. 6(c) shows, the initial average production rate of well TK923H was $125 \mathrm{~m}^{3} / \mathrm{d}$ and the period of water-free oil production period was 78 days. When the barrier extends 50 $\mathrm{m}$ in the $Y$ direction, the calculated critical rate is $87.9 \mathrm{~m}^{3} /$ $\mathrm{d}$, which is lower than the initial average production rate. It is obviously that the initial average production was too high, and the bottom water rose too fast, so the water-free oil production period was only 78 days.

The results calculated from the equations deduced in this paper provide a reasonable explanation to water breakthrough time.

\section{Conclusions}

1) Barriers have a significant effect on the critical rate of horizontal wells in bottom water reservoirs. The presence of impermeable barriers can increase the critical rate of oil wells and delay water breakthrough.

2) The size and location of barriers affect the prediction of critical rate. With the increases in the size and the distance of the barrier to the oil-water contact, the critical rate increases. As the barrier size increases, the critical rate gradually approaches a constant.

3) The method proposed in this paper can be used to predict the critical rate of horizontal wells in bottom-water reservoirs with an impermeable barrier and be applied to investigate water cresting in horizontal wells.

\section{Acknowledgements}

This work was supported by the National Science and Technology Major Project of China (No. 2011ZX05010-003) and the National Natural Science Foundation of China (No. 10902093).

\section{References}

Aggour M A and Khana I S. HELE-SHAW model study of horizontal well performance in reservoir with gas cap and bottom water drive. Petroleum Science and Technology. 2001. 19(5-6): 661-672

Aulie T, Asheim H, Oudeman P, et al. Experimental investigation of cresting and critical flow rate of horizontal wells. SPE Advanced Technology Series. 1995. 3(1): 207-215 (Paper SPE 26639)
Bahadori A. Determination of well placement and breakthrough time in horizontal wells for homogeneous and anisotropic reservoirs. Journal of Petroleum Science and Engineering. 2010. 75(1-2): 196-202

Borisov J P. Oil production using horizontal and multiple deviation wells, Nedra, Moscow. Translated into English by Strauss J, Edited by Joshi S D. Philips Petroleum CO. The R \&D Library Translation, Bartlesville, Okahoma, 1984

Chaperon I. Theoretical study of coning toward horizontal and vertical wells in anisotropic formations: Subcritical and critical rates. Paper SPE 15377 presented at the SPE Annual Technical Conference and Exhibition, 5-8 October 1986, New Orleans, Louisiana

Chen Y Q. Derivation and correlation of production rate formula for horizontal wells. Xinjiang Petroleum Geology. 2008. 29(1): 68-71 (in Chinese)

Cheng L S, Lang Z X and Zhang L H. Reservoir engineering problem of horizontal wells coning in a bottom water drive reservoir. Journal of Petroleum of University. 1994. 4 (18): $43-46$ (in Chinese)

Chierici G L, Ciucci G M and Pizzi G. A sysmtematic study of gas and water coning by potentiometric models. Journal of Petroleum Technology. 1964. 16(8): 923-929

Fan Z F and Lin Z F. A study of the critical rate of a horizontal well in a reservoir with bottom-water drive. Petroleum Exploration and Development. 1994. 21(1): 65-70 (in Chinese)

Fan Z F. Study of productivity formula of horizontal wells in bottomwater drive reservoirs. Petroleum Exploration and Development. 1993. 20(1): 71-75 (in Chinese)

Giger F M, Resis L H and Jourdan A P. The reservoir engineering aspects of horizontal drilling. Paper SPE 13024 presented at the SPE Annual Technical Conference and Exhibition, 16-19 September 1984, Houston, Texas

Giger F M. Analytic two-dimensional models of water cresting before breakthrough for horizontal wells. Paper SPE 15378 presented at the SPE Annual Technical Conference and Exhibition, 5-8 October 1986, New Orleans, Louisiana

Gourley E N and Ertekin T. Application of a local grid refinement technique to model impermeable barriers in reservoir simulation. Paper SPE 39216 presented at the SPE Eastern Regional Meeting, 22-24 October 1997, Lexington, Kentucky

Gunning J, Paterson L and Poliak B. Coning in dual completed systems. Journal of Petroleum Science and Engineering. 1999. 23(8): 27-39.

Guo B and Lee R L. A general solution of gas/water coning problem for horizontal wells. Paper SPE 25050 presented at the European Petroleum Conference, 16-18 November 1992a, Cannes, France

Guo B and Lee R L. Determination of the maximum water free production rate of a horizontal well with water-oil interface cresting. Paper SPE 24324 presented at the SPE Rocky Mountain Regional Meeting, 18-21 May 1992b, Casper, Wyoming

Hou J G. Prediction of interbeds intercalated into complex heterogeneous reservoirs at a high water cut stage. Petroleum Science. 2007. 4(3): 26-30

Jin L, Wojtanowicz A K and Hughes R G. An analytical model for water coning control installation in reservoir with bottom water. Journal of Canadian Petroleum Technology. 2010. 49(5): 65-70 (Paper SPE 137787)

Joshi S D. Augmentation of well productivity using slant and horizontal wells. Journal of Petroleum Technology. 1988. 40(6): 729-739 (Paper SPE 15375)

Karp J C, Lowe D K and Marusov N. Horizontal barriers for controlling water coning. Journal of Petroleum Technology. 1962. 14(7): 783790

Khan A R. A scaled model study of water coning. Journal of Petroleum Technology. 1970. 22(6): 771-776

Li C L and Song H C. Computation formula of critical production oil wells in reservoirs with bottom water and confining bed. Petroleum 
Geology \& Oilfield Development of Daqing. 1993. 12(4): 43-46 (in Chinese)

Li C L. A formula for prediction of breakthrough of water in wells producing from bottom water reservoirs with barriers. Petroleum Geology \& Oilfield Development of Daqing. 1997. 16(4): 49-50 (in Chinese)

Mungan N. A theoretical and experimental coning study. SPE Journal. 1975. 15(3): 247-254

Muskat M and Wyckoff R D. An approximate theory of water coning in oil production. Petroleum Transactions, AIME. 1935. 114: 144-163

Ould-Amer Y, Chikh S and Naji H. Attenuation of water coning using dual completion technology. Journal of Petroleum Science and Engineering. 2004. 45 (1-2): 109-122

Ozkan E and Raghavan R. A breakthrough time correlation for coning toward horizontal wells. Paper SPE 20964 presented at European Conference, 22-24 October 1990, The Hague, Netherlands

Papatzacos P, Herring T M, Martinsen R, et al. Cone breakthrough time for horizontal wells. Paper SPE 19822 presented at the SPE Annual Technical Conference and Exhibition, 8-11, October 1989, San Antonio, Texas

Permadi P and Jayadi T. An improved water coning calculation for horizontal wells. Paper SPE 133162-MS presented at Oil and Gas Conference and Exhibition, 26-28 October 2010, Moscow, Russia

Permadi P, Lee R L and Kartoatmodjo R S T. Behavior of water cresting under horizontal wells. Paper SPE 30743 presented at the SPE Annual Technical Conference and Exhibition, 22-25 October 1995, Dallas, Texas

Permadi P. Water cresting behavior under high angle wells: An experimental investigation. Paper SPE 35715 presented at the Western Regional Meeting, 22-24 May, 1996, Anchorage, Alaska

Shirman E I. Experimental and theoretical study of dynamic water control in oil wells. Ph.D Dissertation. Louisiana State University, Baton Rouge, May 1998

Siddiqi S S and Wojtanowicz A K. A study of water coning control in oil wells by injected or natural flow barriers using scaled physical model and numerical simulator. Paper SPE 77415 presented at the SPE Annual Technical Conference and Exhibition, 29 September-2 October 2002, San Antonio, Texas

Smith C R and Pirson S J. Water coning control in oil wells by fluid injection. SPE Journal. 1963. 3(4): 314-326,

Strickland R F. Artificial barriers may control water coning-1. Oil and Gas Journal. 1974. October: 61-64

Wojtanowicz A K, Hui X and Zaki B. Segregated production method for oil wells with active water coning. Journal of Petroleum Science and Engineering. 1994. 11(1): 21-35

Yue P, Chen X F and Feng R P. Determine the reasonable production parameters in bottom water oil reservoir. The 5th International Conference of State Key Laboratory of Oil and Gas Reservoir Geology and Exploitation, Southwest Petroleum University, Chengdu, China. 2009, 9: 834-841 (in Chinese)

Yue P. Study of theories of horizontal well productivity prediction and formulas of critical parameters in bottom water reservoirs with horizontal well. MS Dissertation. Southwest Petroleum University. Chengdu, Sichuan, China. May 2010 (in Chinese)

Zhang L H, Zhao Y L and Liu Z B. A novel steady-state productivity equation for horizontal wells in bottom water drive gas reservoirs. Petroleum Science. 2011. 8(1): 63-69

Zhang P, Wen X H, Ge L Z, et al. Existence of flow barriers improves horizontal well production in bottom water reservoirs. Paper SPE 115348 presented at the SPE Annual Technical Conference and Exhibition, 21-24 September 2008, Denver, Colorado

(Edited by Sun Yanhua) 